\title{
Receptive Fields and Dendritic Structure of Directionally Selective Retinal Ganglion Cells
}

\author{
Guang Yang and Richard H. Masland \\ Program in Neuroscience, Harvard Medical School, Boston, Massachusetts 02114
}

\begin{abstract}
We studied the relationship between the receptive fields of directionally selective retinal ganglion cells and the dendritic arbors of the same cells. The cells were recorded from extracellularly under visual control and then injected with Lucifer yellow. The arbor of Lucifer-filled dendrites could then be directly compared with the properties of the receptive field.
\end{abstract}

A large population of on-off directionally selective cells was injected and drawn. The directionally selective ganglion cells had bistratified receptive fields similar to those previously described by others in the central retina. In the periphery, the dendritic fields became larger, rounder, and sparser than centrally. The diameters of the dendrites were measured in living or lightly fixed retinas; they were found to be somewhat larger than previously estimated by electron microscopy. The local structure of the dendritic arbor bore no obvious relation to the directional properties of the cell.

The receptive fields of most cells were centered symmetrically around their dendritic fields. For about $10 \%$ of the cells, however, the receptive field was displaced. The displacement was always toward the preferred direction, relative to the dendritic field. The meaning of these shifts is not clear.

In both cases, the diameter of the receptive field exceeded the diameter of the dendritic field only slightly; in our sample, the diameters of the receptive fields averaged $6 \%$ larger than the dendritic fields. This means that the neurons afferent to the directionally selective ganglion cells must either have narrow dendritic fields or, if they are wide spreading, have dendrites that do not conduct effectively along their length.

It also means that the observed spread of neurobiotin between DS ganglion cells (Vaney, 1991) must be due to a very few gap junctions, or to some mechanism other than a gap junction.

[Key words: injection, amacrine, anatomy, physiology]

Directionally selective (DS) retinal ganglion cells, as their name implies, respond unequally when a stimulus moves across their receptive field in different directions (Barlow and Levick, 1965; Wyatt and Daw, 1975; Amthor et al., 1984). The directional preference is somehow created by converging inputs from ama-

\footnotetext{
Received Nov. 11, 1993; revised Feb. 7, 1994; accepted Feb. 24, 1994.

We thank Michael Beauchamp for assistance with the stimulus-generating program. This article was supported by NIH Grant R37-EY01075.

Correspondence should be addressed to Dr. Richard Masland, Wellman 429, Massachusetts General Hospital, Boston, MA 02114.

Copyright (C) 1994 Society for Neuroscience $0270-6474 / 94 / 145267-14 \$ 05.00 / 0$
}

crine and bipolar cells onto the DS ganglion cell, but the exact mechanism remains unknown (Torre and Poggio, 1978; Koch et al., 1982; Borg-Graham and Grzywacz, 1991). In the work described here, we measured the relationship between the size of the dendritic field of the DS cell and its receptive field. To do so, we developed methods that allow visualization of the cell's dendritic arbor and plotting of the same cell's receptive field in living retinas.

One question that we hoped to answer was how inputs from starburst amacrine cells converge spatially upon the DS cell. As will be discussed in detail later (see Discussion), these amacrine cells have wide dendritic spreads; if this is so, and if the starburst cells make excitatory synapses upon the DS ganglion cell, they would be expected to expand the receptive fields of the ganglion cells beyond the spread of the ganglion cell's own dendrites. We sought to lcarn whether or not that is the case. A short report of part of this work has been published (Yang and Masland, 1992). Here we present further experiments and a more complete analysis of the results.

In addition, we show the dendritic structure of a number of identified DS ganglion cells. The DS cells have been the subject of much computational modeling, and many of the models depend heavily on assumptions about their dendritic dimensions (Rall, 1964; Miller and Bloomfield, 1983, Koch et al., 1984). However, published micrographs of DS ganglion cells are few, and all of them are from fixed tissue (Famiglietti, 1983, 1991; Amthor et al., 1984, 1989). We wanted to estimate-within the coarse limits set by light microscopy - the diameter of the dendrites and the amount by which it decreases from proximal to distal.

Finally, we address the issue of physiological coupling between the dendrites of adjacent DS ganglion cells. Vaney (1991) has reported that injection of neurobiotin or biocytin into DS ganglion cells results in spread of the marker compound into many adjacent DS ganglion cells. This suggests that the cells might be connected by gap junctions. If that is the case, the gap junctions should expand the DS ganglion cells' receptive fields, because of the lateral spread of current from ganglion cell to ganglion cell.

\section{Materials and Methods}

Retinal preparations. Adult New Zealand White rabbits were used. The animal was anesthetized with an intramuscular injection of a 1:1 mixture of ketamine $(50 \mathrm{mg} / \mathrm{ml})$ and xylazine $(20 \mathrm{mg} / \mathrm{ml}), 1.5-2.0 \mathrm{cc}$ for a $4-5$ $\mathrm{lb}$ rabbit. The eye was protopsed, and $10 \mu \mathrm{l}$ of $1 \%$ Fast blue (Sigma) was injected into the optic nerve through a slit in the conjunctiva. The animal was then allowed to recover from anesthesia. Two to three days later the dark-adapted animal was deeply anesthetized with the same mixture of ketamine and xylazine in combination with an ether mask, 

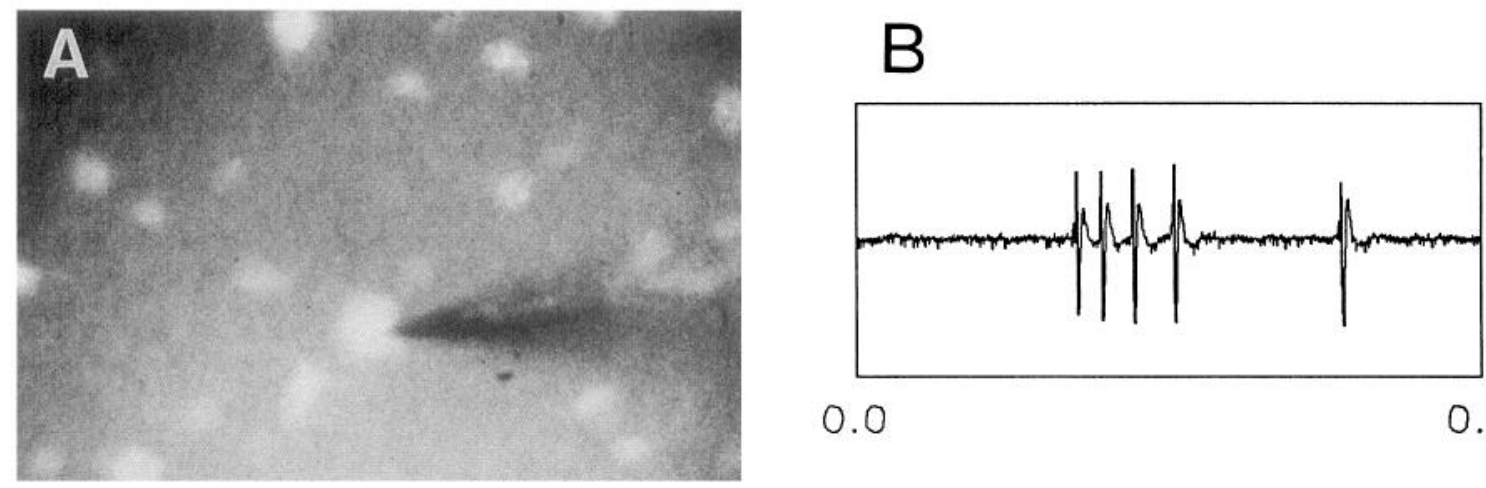

0.0

0.1
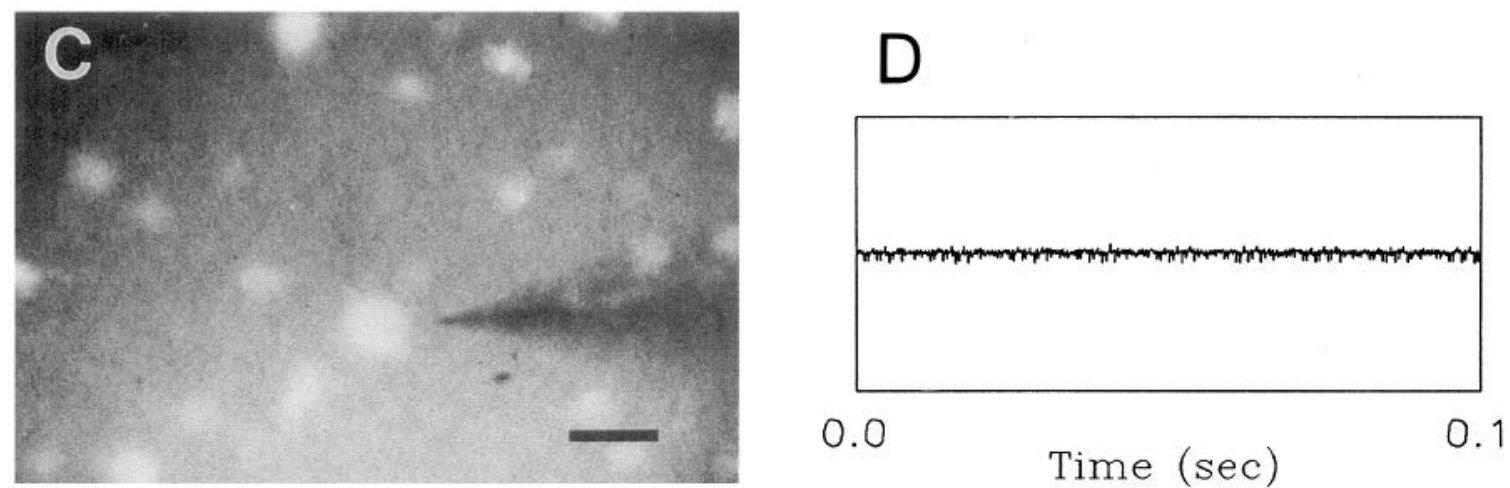

Figure 1. Video images of retinal ganglion cells retrogradely labeled with Fast blue and records of action potentials recorded from them. Under visual control, an electrode was advanced toward a DS ganglion cell, tentatively identified by its medium-to-large cell body and smooth surface. Only when the electrode was close to the cell body were large action potentials recorded $(A$ and $B)$. When the electrode was withdrawn more than $10 \mu \mathrm{m}$ from the cell body, no neuronal activity was recorded $(C$ and $D$ ). The signals were filtered with a bandwidth of $200 \mathrm{~Hz}$ to $20 \mathrm{kHz}$. The cell was confirmed as DS by subsequent physiological study. Scale bar, $50 \mu \mathrm{m}$.

and the eye was removed. The animal was killed by intravenous injection of T-61 Euthanasia solution (Hoechst Roussel) without awakening from anesthesia.

The fundamental procedures for isolating, maintaining, and recording from a living rabbit retina in vitro were those developed and described in detail by Ames and his colleagues (Masland and Ames, 1976; Ames and Nesbett, 1980). All were carried out under dim red illumination. The eye was hemisected at the equator, and the lens and vitreous humor were lifted away. The posterior eyecup was everted over the round head of a Teflon rod under Ames medium that had been equilibrated with $95 \% \mathrm{O}_{2}$ and $5 \% \mathrm{CO}_{2}$. The retina was gently teased away from the pigment epithelium.

A small piece of the retina was cut away for recording, and the remaining tissue was maintained in Ames medium in a $20 \mathrm{ml}$ rocking tube, which was placed on a rocker at room temperature. The small piece of retina was mounted on a piece of filter paper (\#40, ashless, Whatman) with the ganglion cell layer uppermost in a superfusion chamber (see Ames and Masland, 1989). A hole had been cut in the center of the filter paper to allow stimuli to be projected from below onto the photoreceptor surface. The retina was held down by nylon mesh weighted by a platinum ring, and was superfused at $1 \mathrm{ml} / \mathrm{min}$. The chamber was mounted on the stage of a Leitz upright fluorescence microscope and maintained at $35^{\circ} \mathrm{C}$.

Identification of directionally selective cells. Ganglion cell bodies labeled by Fast blue were viewed through Leitz filter cube D (exciting wavelength, $355-425 \mathrm{~nm}$ ) and a long-working-distance objective (Zeiss $40 \times$ water immersion). To prevent photodamage and bleaching of the photoreceptors caused by the ultraviolet illumination, a blocking filter (Schott, BG12) was placed in front the light house, and an intensified CCD camera (Dage-MTI) with image processing (Image-1) was used for minimum intensity and exposure. In the later experiments, a foot pedal-controlled electronic shutter (Uniblitz) mounted in front of the florescent light house, for short exposures of the exciting light, was routinely used alone without the CCD camera. The two methods gave equivalent results. DS cells could be identified to a large extent by the appearance of their somata, which were medium to large in size (about
$20-30 \mu \mathrm{m}$ ) in diameter, and had a smooth outline. Visual identification was subsequently confirmed by extracellular recordings.

Recordings and light stimulation. A tungsten-in-glass electrode (tip size, $10-20 \mu \mathrm{m}$; resistance, $\sim 1 \mathrm{M} \Omega$ ) was advanced toward a targeted cell under visual guidance. Signals were amplified, filtered, and fed into a Schmitt trigger that generated a digital input to a computer equipped with a data acquisition board (Lab-PC). The signals were also displayed on a oscilloscope and fed into an audio monitor.

The stimuli consisted of flashing spots and moving bars of various sizes. They were generated by a computer on a monitor (Omni Vision), which was imaged through the condenser of the microscope onto the photoreceptor surface of the retina. The same stimuli were repeated on a slave monitor covered with a transparency for plotting of receptive fields. The stimuli were controlled automatically or were manually positioned and flashed by using a mouse. The luminance of the stimulus was about $10 \mathrm{~cd} / \mathrm{m}^{2}$ (measured on the video monitor), while background illumination was kept at around $0.1 \mathrm{~cd} / \mathrm{m}^{2}$.

Plotting receptive field centers. To plot the boundary of a DS cell's receptive field center, both the traditional manual method and a computer-controlled automated method were used. For manual plotting, a flashing spot $(50 \mu \mathrm{m})$ was positioned by using a mouse. The boundary position where a response could just be evoked was judged by listening to the cell's response on an audio monitor, and was marked on the transparency on the slave monitor. This procedure was repeated at a new location about $30 \mu \mathrm{m}$ away until a smooth boundary was obtained. This entire process involved testing $50-100$ positions on the monitor, and typically took $10-20 \mathrm{~min}$ to complete. For automated plotting, a flashing spot (usually $50-80 \mu \mathrm{m}$ in diameter) was presented with $50 \mu \mathrm{m}$ spacing across a large area covering the retina, and the number of spikes evoked at each location was summed for 5-10 trials. The border was drawn at the position where the response was $80 \%$ below the peak response (number of spikes including both on and off responses) that was evoked in the receptive field center. Since the rolloff of response at the border of the DS cells was usually quite steep, determination of the level of $80 \%$ attenuation could be done graphically; sophisticated mathematical tools were not used. 
In some experiments, the border of the receptive field center was also examined with a mouse-controlled spot moving slowly in the preferred direction. The border obtained from the moving stimulus was always found to be close to that obtained from the flashing one. This could be done precisely only for spots entering the receptive field center from the preferred side: on the null side, the spot had to move outward from the receptive field in order to evoke responses; since one then had to judge the cessation of the response, it was more difficult to determine the border.

Since the stimuli were focused onto the photoreceptor surface, light entered the photoreceptors in the opposite direction from that in the intact eye. The isolated retina did not always lie perfectly flat in the chamber: this could affect the shape of the mapped receptive field, but the distortion seemed small.

Intracellular injection. After the receptive field had been plotted, the tungsten-in-glass electrode was withdrawn and replaced by a Luciferfilled micropipette, which was used to inject the cell under visual control. Since the ganglion cell bodies were labeled with Fast blue, the cell from which physiological recording had been carried out could be injected without ambiguity. The injection technique was essentially the same as that was used for injection in fixed tissue (Tauchi and Masland, 1984).

For direct comparison of receptive and dendritic fields, the boundary of the receptive field was drawn on the stimulus-generating monitor and projected onto the surface of the retina through the same optical system used for the stimuli. This was done immediately after injection and without any movement of the retina. Extra care was taken to ensure that the soma location, marked on the slave monitor relative to the receptive field before injection, remained unchanged after the injection. The borders of both receptive field centers and dendritic fields were then directly observed and compared. Video pictures and/or conventional micrographs were taken, and drawings of both fields were also made from the microscope.

Immunohistochemistry of Lucifer-injected cells. At the end of the session, the tissue was removed from the perfusion chamber and processed with immunohistochemistry to convert Lucifer yellow to a permanent product. It was fixed in $4 \%$ paraformaldehyde for $2 \mathrm{hr}$. Tissue that had been injected with Lucifer yellow was incubated in $0.5 \%$ biotinylated anti-Lucifer yellow (Molecular Probes) overnight, processed by a standard avidin-biotin procedure (Elite $A B C$, Vector Lab), and reacted with diaminobenzidine (DAB). Processed retinas were coverslipped in $40 \%$ glycerol, examined under the microscope, and then stored at $4^{\circ} \mathrm{C}$.

Population of cells. We studied the physiology and/or morphology of a total of 102 DS ganglion cells. For 68 cells, the receptive field was completely plotted and the dendrites were completely filled by Lucifer yellow. For the remaining 34 cells, we had some uncertainty as to the receptive field boundary, or (more commonly) the distal dendrites were incompletely stained. In the early studies we did not keep careful track of the eccentricity from which the retinal pieces were cut; morphological studies in which eccentricity was an issue (Fig. 3) use data from 79 cells for which that information was available. Systematic analyses of receptive and dendritic field sizes as a function of eccentricity (Figs. 9, 11, 13) were made for a population of 50 cells for which we were confident of the receptive field map, the filling of the injected cell, and the retinal eccentricity. Results from cells for which partial information was available were always consistent with those from the more complete studies.

\section{Results}

Action potentials recorded from these preparations were large and had normal time courses and waveforms. There were no signs of photodamage to the retina. In fact, the extracellularly recorded spikes were usually larger $(1-2 \mathrm{mV})$ than are generally encountered with metal electrodes, probably because we could optimally place the recording electrode near the cell (Fig. 1). The responses of the cells were brisk and stable for several hours. Even when we intentionally exposed the tissue to the microscope's blue-violet illumination for several minutes (far longer than the exposure used to position the recording electrode, which typically totalled less than $5 \mathrm{sec}$ ), the ganglion cells were not irreversibly damaged. Under the extreme conditions, the ganglion cells initially lost their light responses but they regained their sensitivity to light stimuli within $10-15 \mathrm{~min}$ if the retina was left to recover in the dark.

Because the electrodes were placed visually, there was no question which cell was recorded from. Large action potentials were recorded with these electrodes only when they were very close to a cell body (Fig. $1 A, B$ ). When the electrode was withdrawn more than $10-20 \mu \mathrm{m}$ from the soma, no neuronal activity was encountered (Fig. 1C,D). Usually, spikes were not encountered during the first advancement of the electrode toward the cell body; recording usually required a few advances of the electrode, as though the electrode had to break the Müller cell membranes that surround the ganglion cell body. Figure 1 shows DS cell bodies in the mid-peripheral retina, where the ganglion cell density is lower than in the central retina. For a few cells recorded from the central retina, spikes from more than one cell were recorded by the electrode. That the recordings came from the identified DS cells was independently confirmed in these cases by their morphology.

With some experience, DS cells could be identified with roughly $80 \%$ accuracy from the appearance of their somas. The cell body in the center of the Figure 1 was tentatively identified as DS cell because it was medium sized (between 20 and $30 \mu \mathrm{m}$ in diameter), and had a round outline. Its identity was confirmed by subsequent characterization of its receptive field.

\section{$D S$ cell responses and morphology}

Because of the stability offered by extracellular recording, the cells could be studied for 1-2 hr. In agreement with previous studies (Barlow and Levick, 1965; Wyatt and Daw, 1975; Ariel and Daw, 1982), DS cells responded maximally when the stimuli moved in the preferred direction but weakly when the stimuli moved in the opposite direction. Their directional preferences were independent of the contrast of the stimuli: they had the same directional preference for a white object on a black background or a black object on a white background. When stimulated with a flashing spot, DS cclls gave on-off transient responses. Movement over a small distance within the receptive field evoked clear DS responses, indicating the existence of subunits. If the spot extended very much beyond the DS cell's receptive field center, the response became smaller, consistent with evidence that DS cells have a silent surround that inhibits the center response (Barlow and Levick, 1965; Wyatt and Daw, 1975).

Figure 2 shows responses of an on-off DS cell to movements in different directions in relation to its dendritic tree (as later revealed from intracellular injection of Lucifer yellow into the cell). The stimulus was a bright bar $80 \times 120 \mu \mathrm{m}$ on a dark background; the leading and trailing responses in the histograms were evoked by the leading edge moving into and trailing edge moving out of the receptive field. The preferred direction in the figure is toward the upper left corner (Fig. $2 A$, histograms $b, c$ ). The longest axis of the dendritic field was $550 \mu \mathrm{m}$, and the dendritic arbor was bistratified. In the micrograph, the on sublamina is in focus, while the axon and the off sublamina are out of focus. At the bottom of Figure 2, are separate drawings of dendrites in the on sublamina (left) and the off sublamina (right). This cell was located in the inferior temporal part of the retina, approximately $6 \mathrm{~mm}$ below the visual streak. Its morphology is similar to that reported by Amthor et al. $(1982,1989)$ in a sample of cells from the central retina. The dendritic arbors often curve back toward the cell bodies, forming a regular meshwork that covers the field uniformly. 

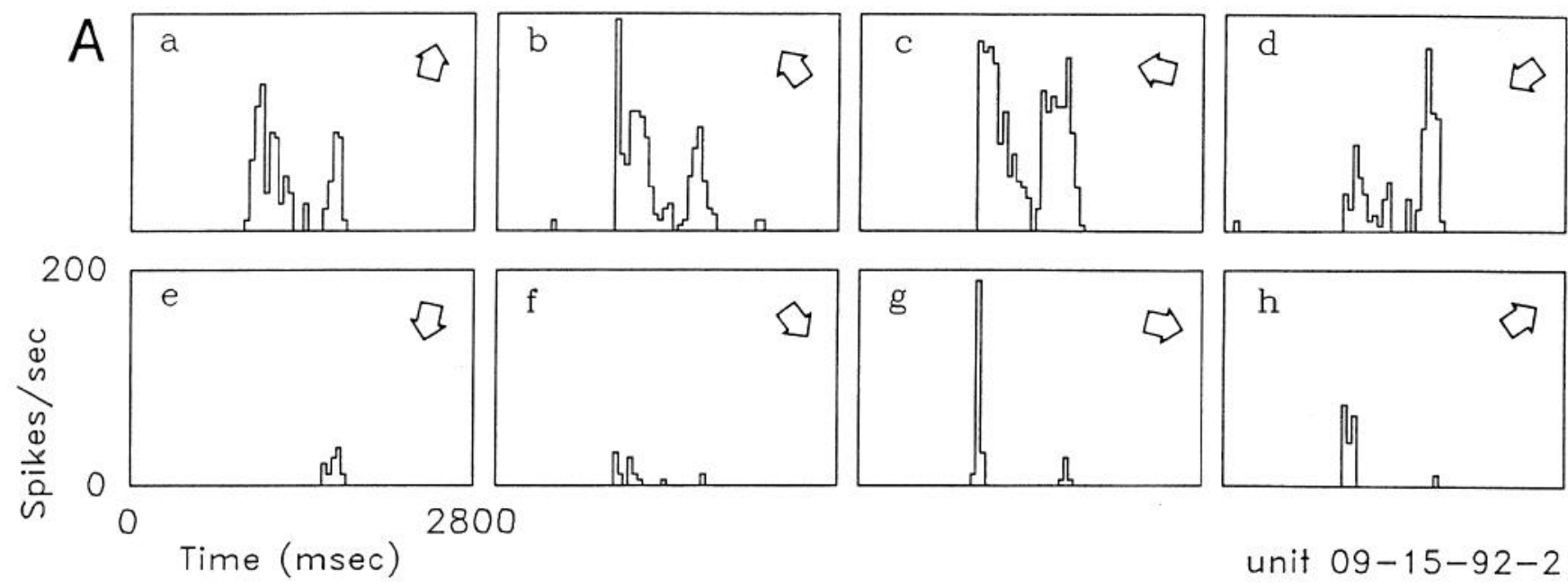

B

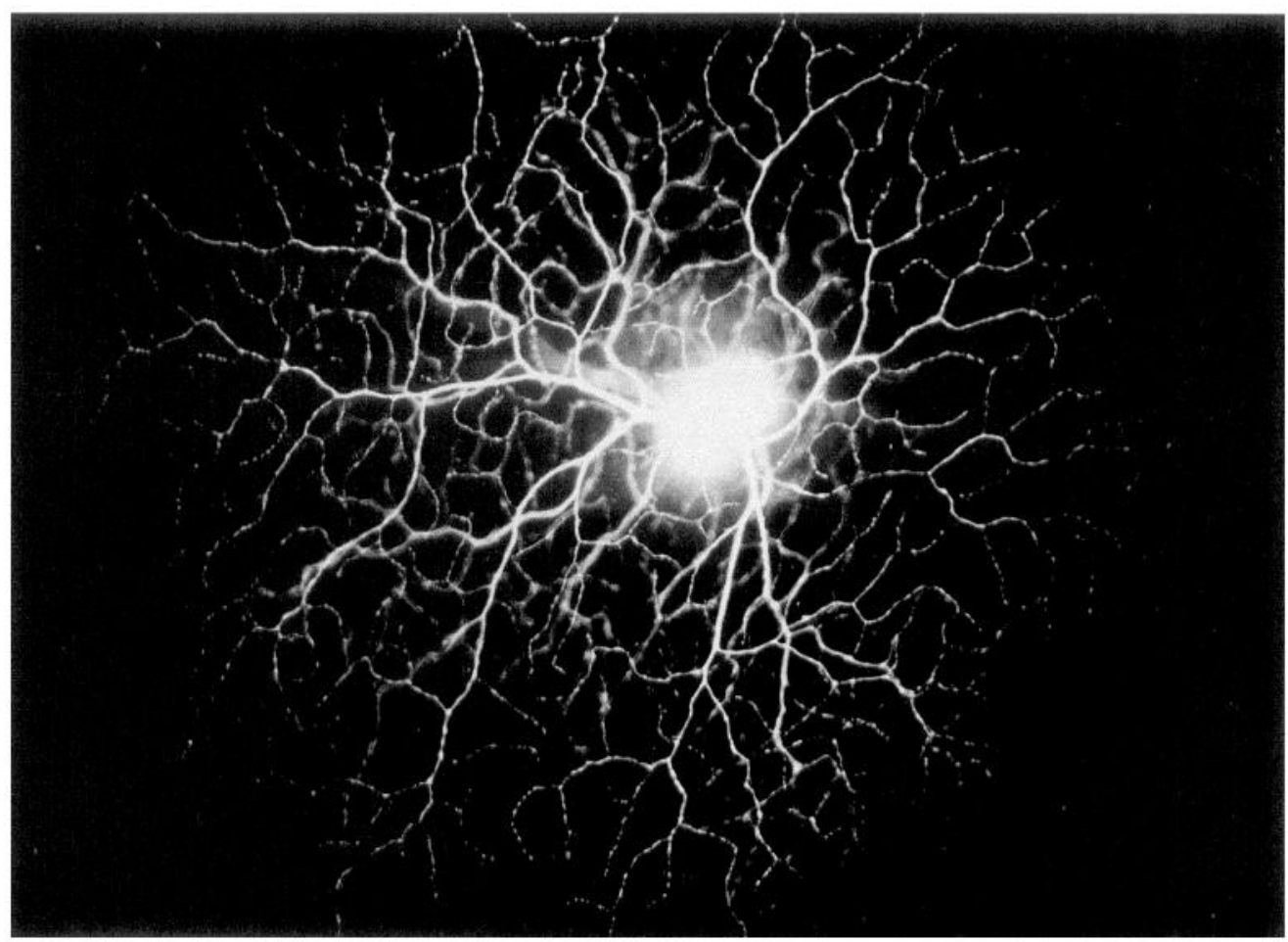

\section{Inner arbor}

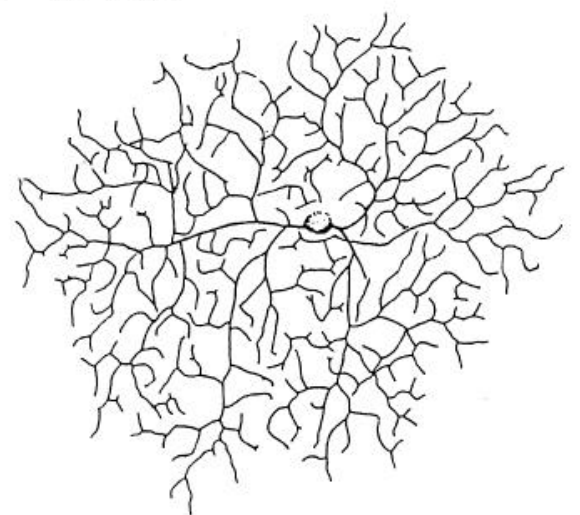

Outer arbor

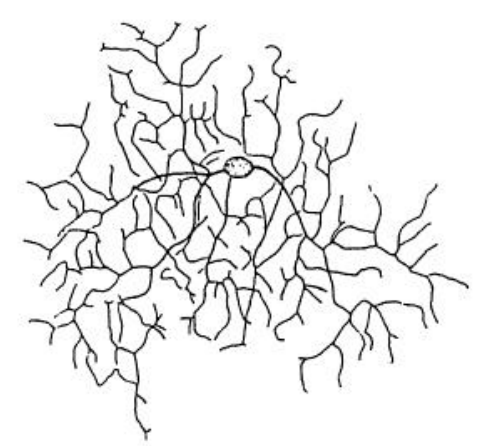

Figure 2. A, Response histograms of an on-off DS cell to movements in eight different directions $(a-h)$. Responses are expressed as spikes/sec, averaged for five trials. Positioning of the electrode and subsequent intracellular injection of Lucifer yellow were conducted under visual control. The stimulus was a white bar $(80 \times 120 \mu \mathrm{m})$ moving at a constant speed of $860 \mu \mathrm{m} / \mathrm{sec}$ (equivalent to 5 degrees/sec) on a dark background. The arrows indicate the directions in which the test bar crossed the dendritic arbor of the cell shown below. $B$, The cell was injected with Lucifer yellow to reveal its dendritic morphology. The dendrites were bistratified. In the micrograph, the on sublamina is in focus and the off sublamina and axon out of focus. The longest axis of the dendritic field covers $550 \mu \mathrm{m}$. Drawings below are of the dendrites located within the on sublamina (left) and the off sublamina (right). Note that the dendritic field in the off sublamina is smaller than that in the on sublamina. 


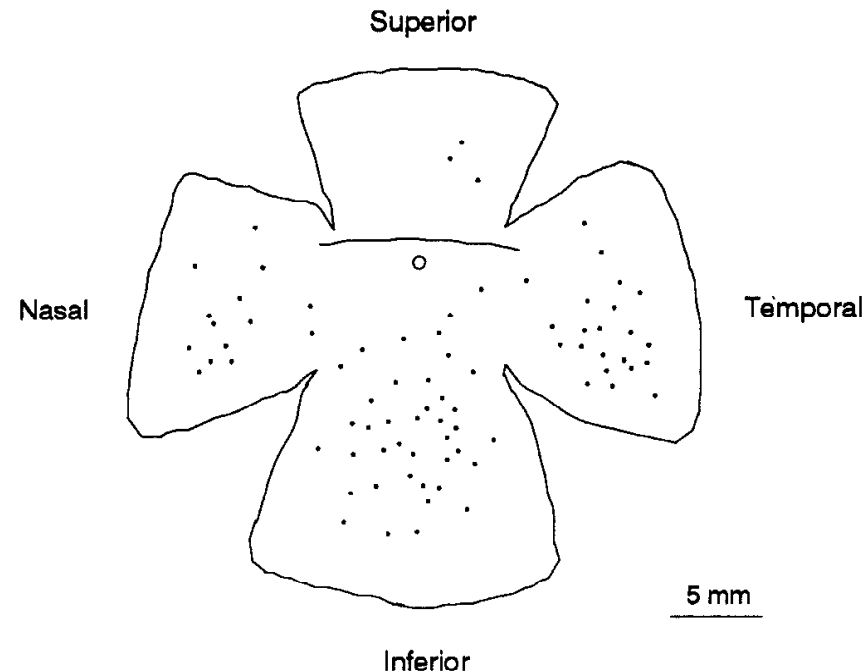

Figure 3. Schematic retina illustrating the relative positions of 79 directionally selective ganglion cells with known locations in this study.

\section{DS cell morphologies at different eccentricities}

The topographical distribution of 79 of our cells is shown schematically in Figure 3. Figure 4 shows the morphology of 10 directionally selective ganglion cells at locations ranging from central retina to periphery. All of them have a similar morphology, characterized by a complicated but regular branching pattern. In the central retina, directionally selective cells are $200-300 \mu \mathrm{m}$ in diameter and tend to be asymmetric. With increasing eccentricity, the dendritic fields become larger and more symmetric. Since the peripheral cells branch more sparsely, the space between their lattice-like branching dendrites becomes larger also. In the retinal periphery, the fields could be over 600 $\mu \mathrm{m}$ in diameter. Arrows at the bottom right corner of each cell in Figure 4 indicate the preferred direction of that cell. We saw no obvious relationship between the preferred directions of the DS cells and their dendritic branching pattern.

\section{Dendritic diameters of DS cells}

Because of their importance for modeling, we tried to make accurate measurements of the dendritic diameters of the directionally selective ganglion cells. Figure 5 shows the dendrites at high magnification from different locations of the dendritic tree. The top row of micrographs shows Lucifer yellow-filled dendrites. They were taken from the living retina in the recording chamber. The bottom row shows the same dendrites after fixation, processing, and DAB staining. The primary dendrites, which descend from the ganglion cell layer into the inner plexiform layer, appeared to be $2-3 \mu \mathrm{m}$ in diameter. As the dendrites branch, they become thinner, eventually to less than $0.5 \mu \mathrm{m}$. Since many branches of dendrites curve back, some of the high order distal tips may actually be spatially positioned near the cell body. As a result, fine dendrites with diameters of less than $0.5 \mu \mathrm{m}$ evenly cover most of the dendritic field.
The dendritic diameters measured from the DAB staining (bottom row) were 10-15\% larger than those obtained from living, unprocessed retinas (top row). Because of this difference, and because of optical uncertaintics in mcasuring thin objects in intact tissue (see Discussion), these values should be treated with much caution. The uncertainty is less for the geometric ratios of main dendrites and daughter dendrites, which seemed the same in the fluorescent and DAB-reacted material. The relationship is shown in Figure 6 for individual dendrites from each of three different DS cells. Note that 6th-order dendrites are not the ultimate ones for these cells, which can branch up to the 10th order. (The higher-order dendrites become difficult to measure, because the staining is fainter.) Figure 6 indicates that the diameters approach a near-asymptote of slightly less than $0.5 \mu \mathrm{m}$ by the 6 th order.

\section{Receptive field center size}

Flashing of a stimulus spot within the receptive field center evoked on, off, or on-off responses. On-off responses predominated, with pure on or pure off responses encountered mostly near the edges of the receptive field. (This may have been related to unequal lateral spread of the cells' on and off arbors.) The rolloff of responses at the receptive field center border was usually very steep, making it easy to determine the boundary position by listening to the cell's response with an audio monitor. Figure 7 shows a response profile to a flashing spot in an automated plotting. A flashing spot $50 \mu \mathrm{m}$ in diameter was presented with $60 \mu \mathrm{m}$ spacing across a large area covering the receptive field, and the number of spikes evoked at each location was averaged for 5-10 trials. The border was drawn at the position where the response was $80 \%$ below the peak response evoked at the receptive field center. We found no significant difference in the receptive field center boundaries obtained by the manual plotting and automated plotting methods, nor did testing with moving stimuli show a boundary different from that established using flashing spots.

\section{The relationship between receptive field and dendritic field diameters}

The two fields were compared by projecting the boundary of the receptive field drawn on the stimulus-generating monitor onto the surface of the retina. The sizes of receptive and dendritic fields were found to be closely matched. Figure 8 shows a micrograph taken of a living retina to show the relationship between the receptive field of a DS cell and its dendritic field. The boundary of the receptive field is visible as a faint ring around the cell. For most cells, the receptive field border lay just outside the tips of the Lucifer-filled dendrites. The relationship between dendritic and receptive fields sizes is plotted in Figure 9. The receptive fields were very slightly larger than the dendritic fields at all retinal eccentricities. The mean amount by which the receptive field exceeded the dendritic field was $6 \%$ $(n=50 ; \mathrm{SEM}=1.4 \%)$.

Figure 4. Dendritic morphology of DS cells at a graded series of eccentricities from visual streak. Arrows at the bottom right of each cell indicate the preferred direction of cell. The orientation of the cells on the page does not correspond to their orientation on the retina. The smallest cells (top row) were encountered near the peak of the streak. The largest (bottom row) were approximately $8 \mathrm{~mm}$ ventral to the streak. Scale bars, $100 \mu \mathrm{m}$. 

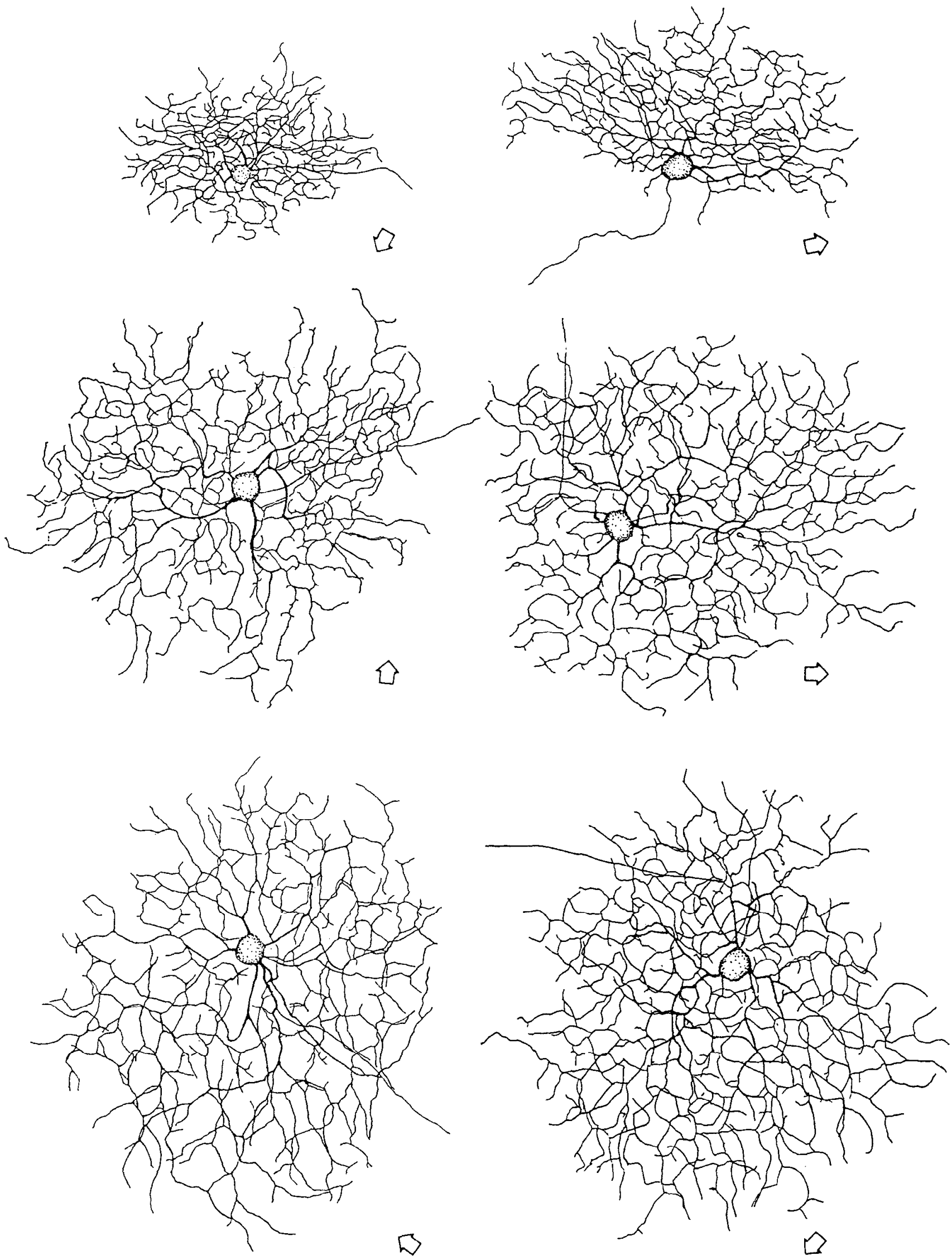


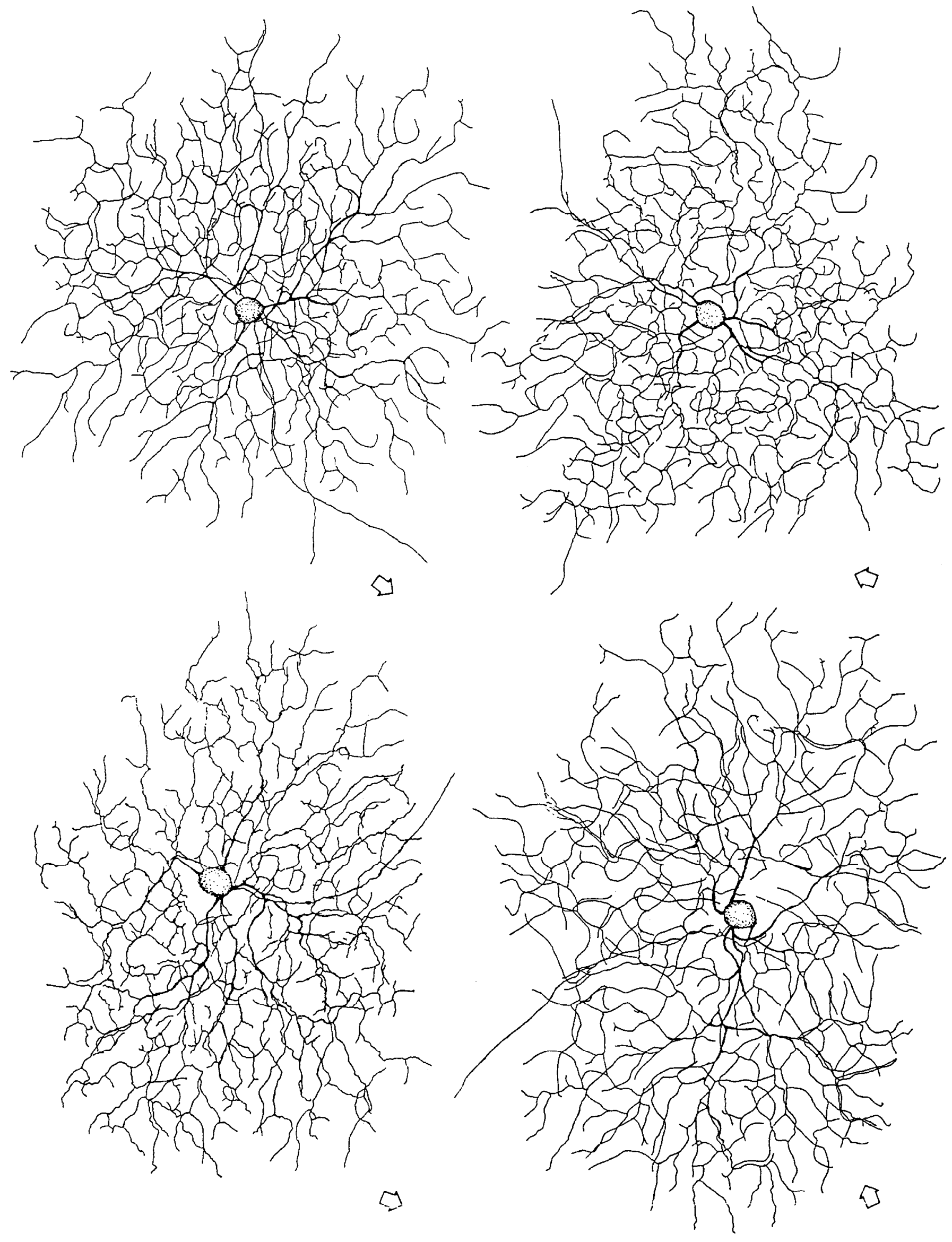




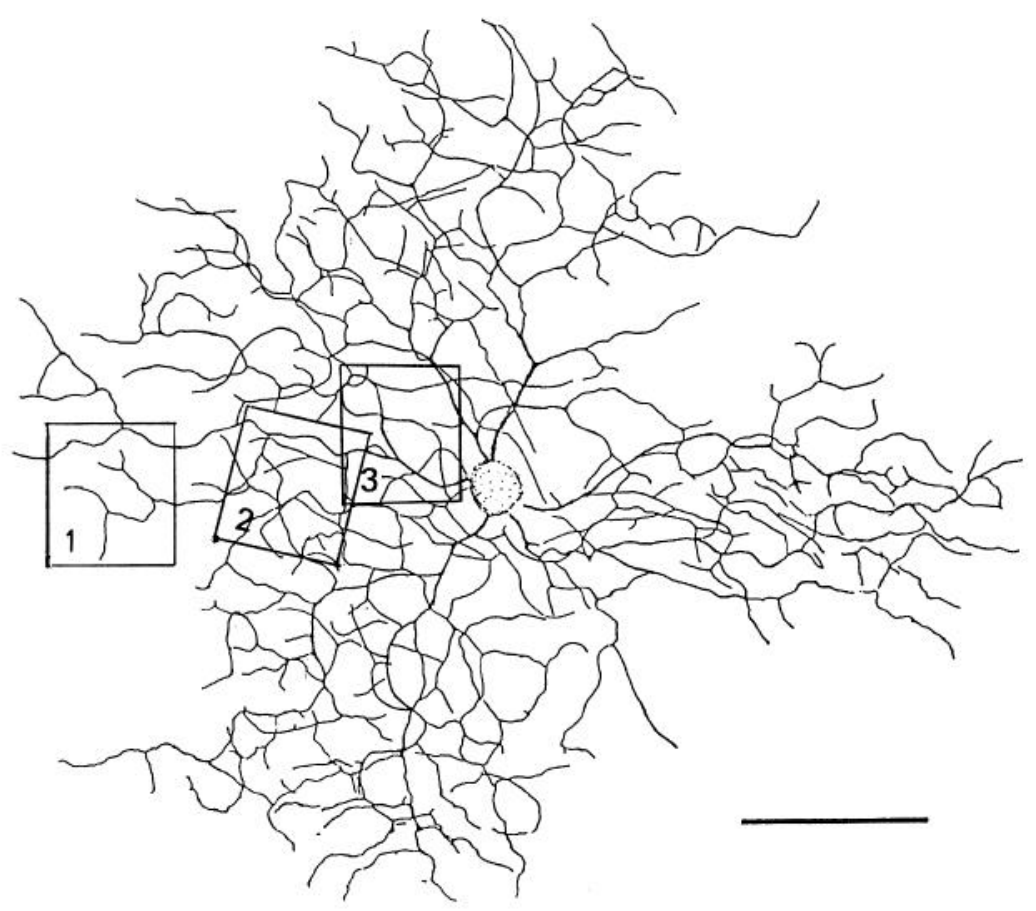

1
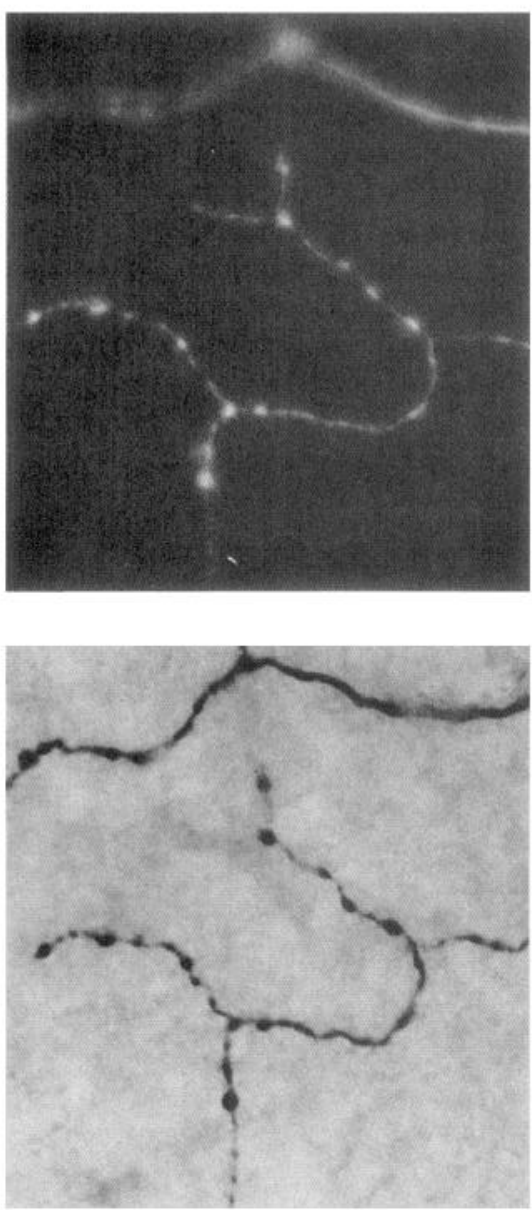

2
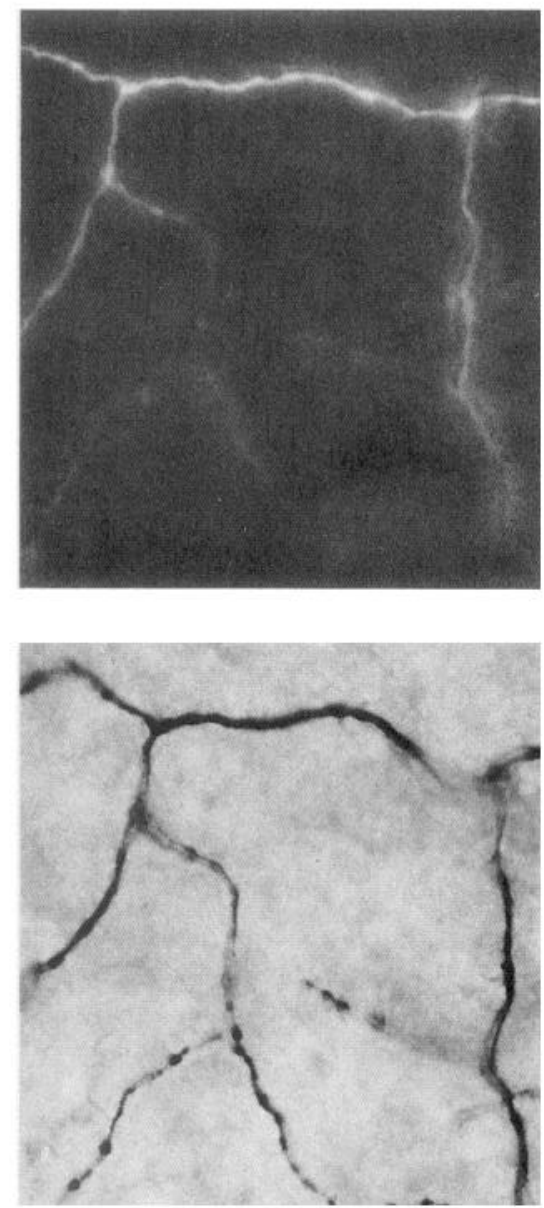

3
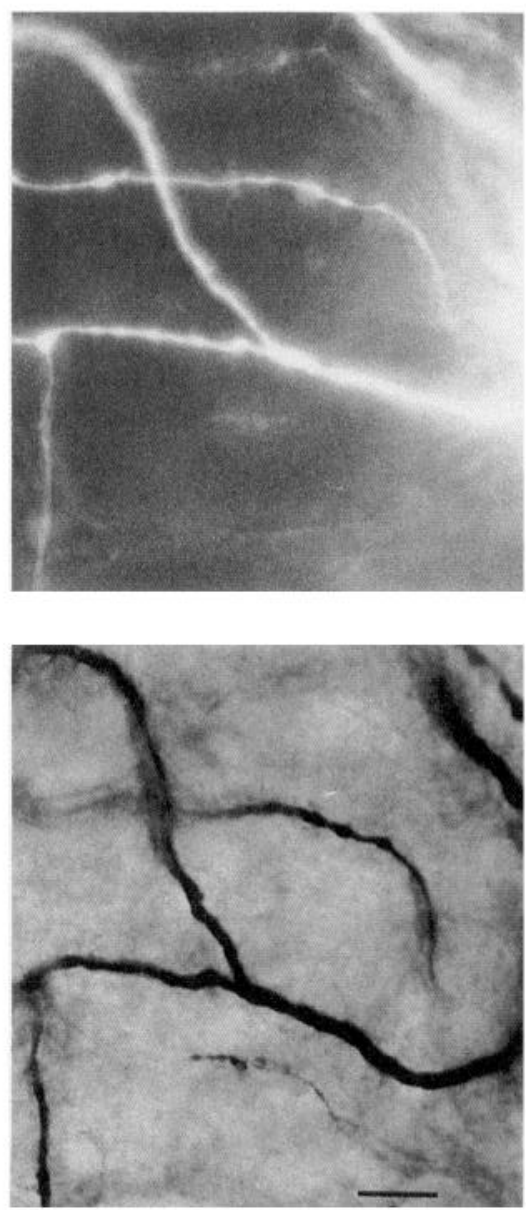

Figure 5. The drawing at the top shows the dendritic arbor of an injected DS cell. Squares indicate the area from which dendrites are shown in higher magnification below. Scale bar, $100 \mu \mathrm{m}$. The Lucifer yellow-stained dendrites (top row of micrographs) were photographed from the living retina in the recording chamber. The bottom row shows the same dendrites at the same magnification but after being fixed and processed immunohistochemically to yield a DAB product. Scale bar, $10 \mu \mathrm{m}$. 

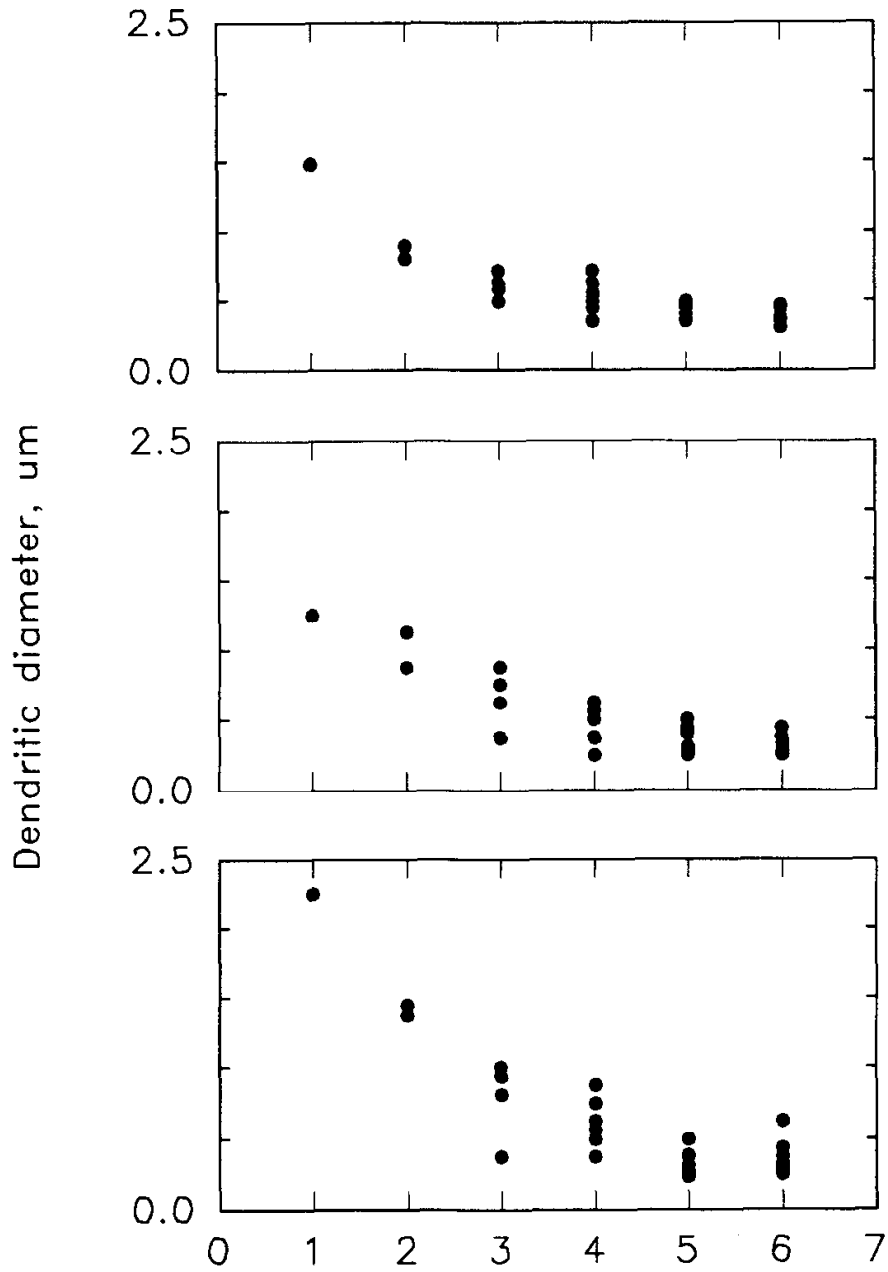

Dendritic branch order

Figure 6. Diameters of the dendrites of various branching orders. The diameters of the dendrites were measured for each of three different cells. The measurements were made from high-magnification photomicrographs of DAB-reacted material.

\section{Displaced receptive fields}

For some cells, the receptive field center was shifted toward the preferred direction relative to the dendritic field. Figure 10 shows an extreme example. The sizes (diameters) of the receptive field and dendritic fields remained closely matched. During the experiment, a shift of a receptive field relative to the dendritic field was at once apparent because of the displacement of the cell body from the center of the receptive field: after the receptive field center was plotted, the location of the cell body (and the tip of the recording electrode) viewed through the microscope was found to be displaced to one side of the receptive field center. However, subsequent injection of Lucifer yellow into these cells revealed that the cell bodies were located in the center of the dendritic field, just as for the nonshifted cells. For those cells showing the shift, the amount of shift varied from $50 \mu \mathrm{m}$ to about $150 \mu \mathrm{m}$. This represents $10-20 \%$ of the total dendritic field diameter, depending on the size of the dendritic field (Fig. 11). The shift of the receptive field was always toward the preferred direction relative to the dendritic fields.

For a summary view of the relationship of receptive fields

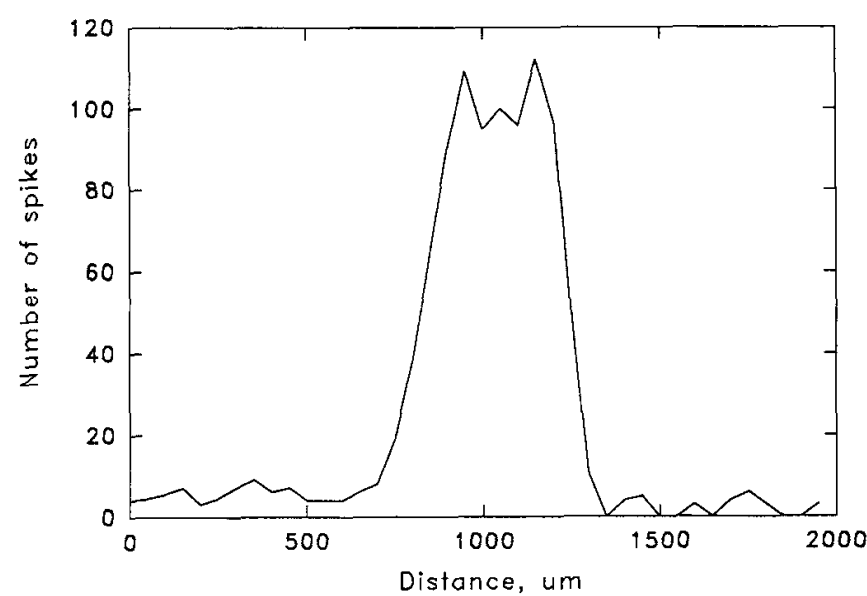

Figure 7. A receptive field center profile obtained from flashing spots with automated plotting. Responses are sums of five trials. Note the steep rolloff at the border of the receptive field.

and dendritic fields, Figure 12 shows 27 cells grouped according to their preferred directions regarding their retinal orientations. Since the recordings were made from a small piece of tissue cut from the retina, we knew the retinal orientation of the preferred directions for only a subset of the cells. For those whose orientations were known $(n=39)$, the distribution of their preferred direction was, inferior to superior, $39 \%$; nasal to temporal, $36 \%$; superior to inferior, $13 \%$; and temporal to nasal, $12 \%$ in the retina. Cells with shifts were found in all four groups, indicating that the shift was not associated with one particular direction. The shift did not seem correlated with the dendritic field's size or location on the retina.

A shift of the receptive field toward the preferred direction is predicted by certain models of directional selectivity (Vaney, 1990; Borg-Graham and Grzywacz, 1991). However, the shift described here happened only for some of the cells. If it were fundamental to directionality, it should be apparent for all DS cells. We therefore sought to unmask a shift in cells that did not originally appear to have one. In these experiments, physostigmine, an acetylcholinesterase inhibitor (Ariel and Daw, 1982), or diazepam, which facilitates GABA inhibition, was added to the medium. Three DS cells were tested with physostigmine (Sigma; $1 \mu \mathrm{M}$ ) in three separate experiments. The cells became more active, their rates of spontaneous firing increased, and their receptive fields became slightly larger after being perfused with physostigmine. However, we did not see an asymmetric enlargement of the receptive fields. Three cells were tested with diazepam in three separate experiments. After perfusion with diazepam (Sigma; $20 \mu \mathrm{M}$ ) the cells' responses to flashing light were reduced. Although the size of the receptive fields increased slightly, no dramatic effects on the symmetry of the receptive field were observed. For the moment, we must conclude that some DS cells have a shift of the receptive field relative to the dendritic field, while others-cells that are surely directionally selective by any usual criterion - can be directional without any displacement of the receptive field.

\section{Discussion}

Our main finding was that the receptive field centers of the DS ganglion cells are very nearly the same size as their dendritic fields - so nearly that the slight excess of receptive over dendritic field could well be due to the lateral extent of the bipolar cells, 
Figure 8. Micrograph taken from the recording chamber, showing the typical relationship between the receptive and dendritic fields of the DS cells. The faint ring surrounding the Lucifer-filled cell shows the boundary of the receptive field. It was drawn on a computer monitor used to plot the receptive field and projected through the same optical system. The fuzziness of the receptive field boundary is due to scattering of light by the retina when the image is focused onto the photoreceptor side. The preferred direction for this cell is indicated by the arrow. There is a close correlation between the locations and size of the two fields. Scale bar, $100 \mu \mathrm{m}$.

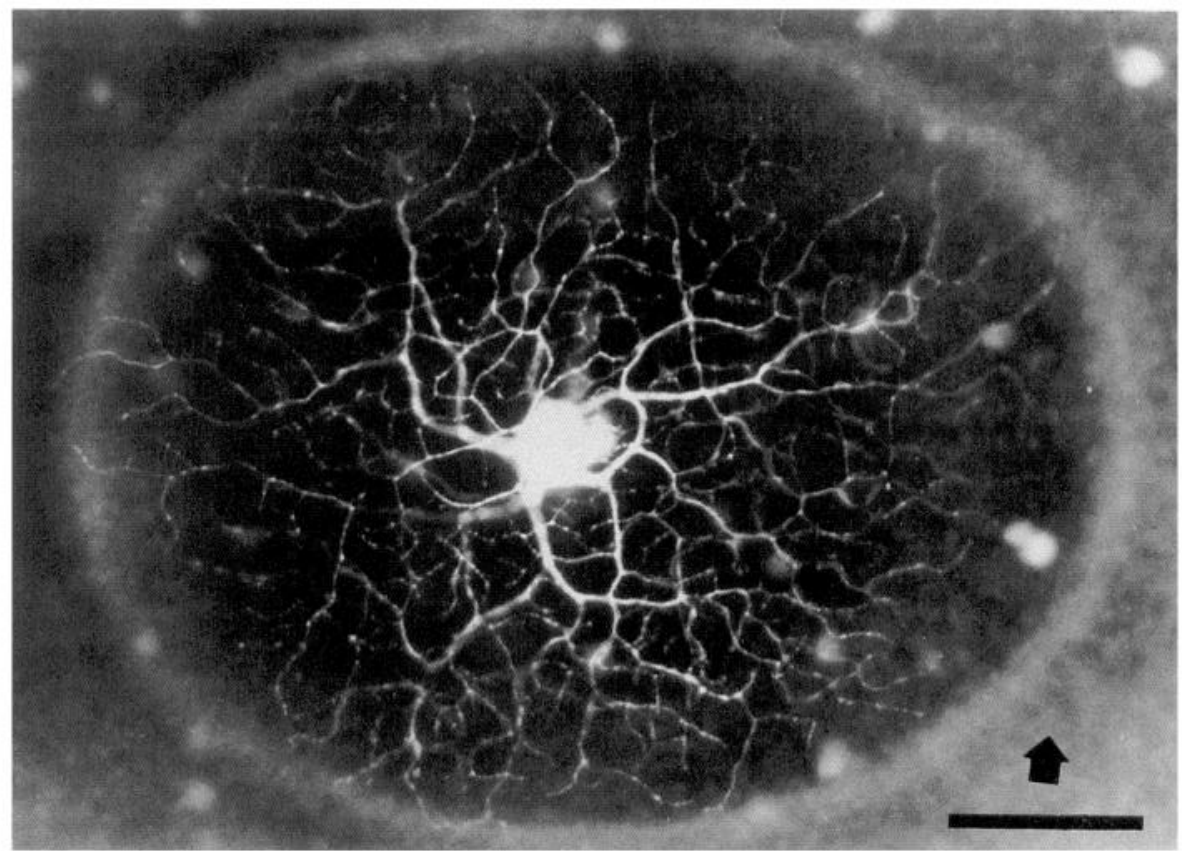

which add their own lateral spread to the width of all inner retinal receptive fields. The measurement of receptive fields was carried out in a simple way, by mapping with single spots, but it seems unlikely that more sophisticated testing would have yielded a fundamentally different result. DS ganglion cells have inhibitory surrounds (Wyatt and Daw, 1975), and this was evidenced in our recordings by weaker responses to long bars than narrow ones. However, this should not much affect the size of the receptive field center; indeed, the effect of the surround would be to make the receptive field center appear smaller than it appeared in our measurements.

DS cells receive other important inhibitory inputs-those responsible for the directional preference. Possibly they contribute

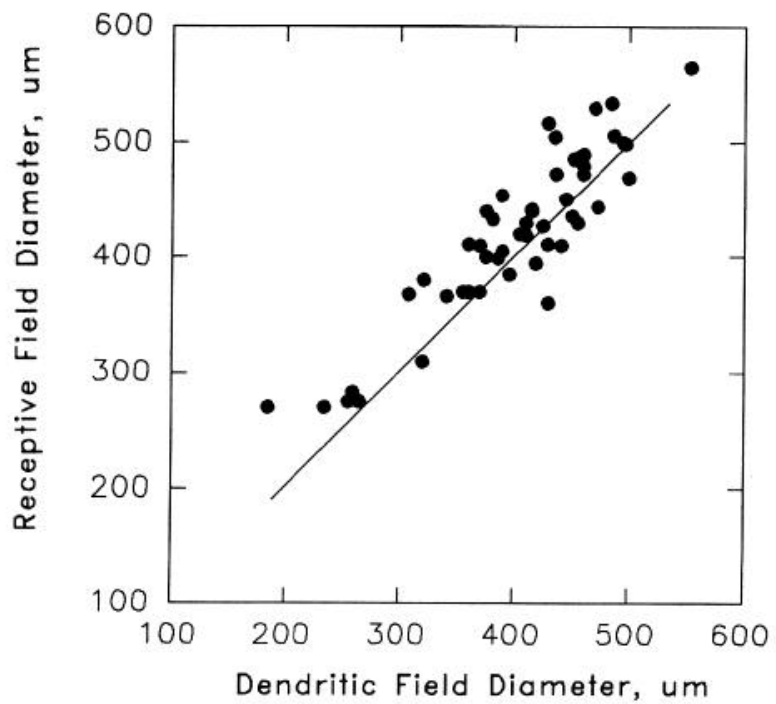

Figure 9. Scatter plot showing the correlation of receptive and dendritic field sizes for 50 DS cells. The diameter expressed here is the average of the widest and smallest diameters. The straight line shows the values expected if the receptive and dendritic fields were identical. to the sharpness of the receptive field boundaries, which were more abrupt than those of ganglion cells that have a simple center-surround organization (Peichl and Wässle, 1983). Given the number and complexity of the inner plexiform layer's lateral connections, it would not be surprising if subtle lateral effects exist outside the boundaries defined by our measurements (Grzywacz et al., 1993). However, moving spots gave the same boundaries as stationary ones in our experiments and there seems little doubt that the region from which the ganglion cell derives its main excitatory drive was accurately defined by our testing.

Comparisons of the dendritic and receptive fields have been made for certain amacrine cells of the rabbit's retina (Bloomfield, 1992a). For technical reasons, the measurements could

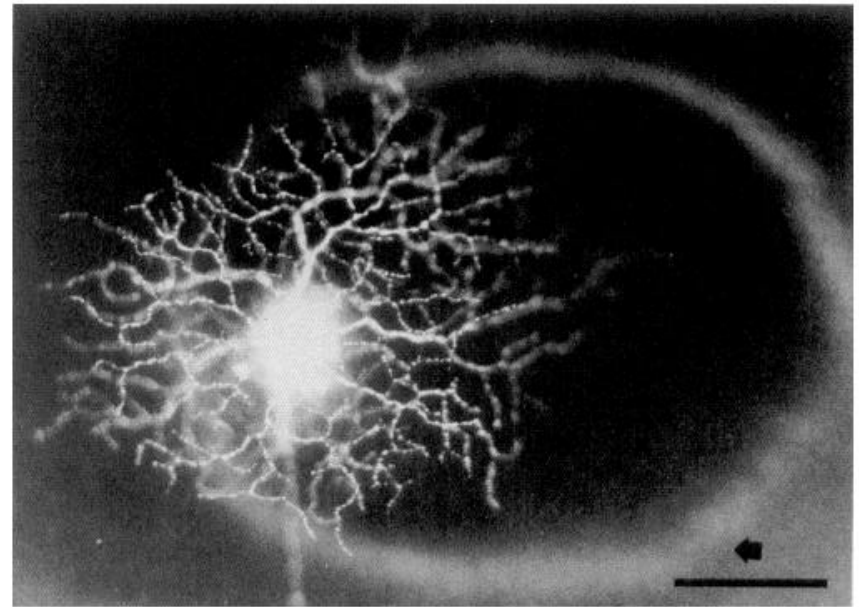

Figure 10. For this cell, there is a shift of the receptive field toward the preferred direction relative to the dendritic field. The cell body, which was in the center of the dendritic field, was not at the center of the receptive field. Arrow indicates the preferred direction of the cell. Scale bar, $100 \mu \mathrm{m}$. 


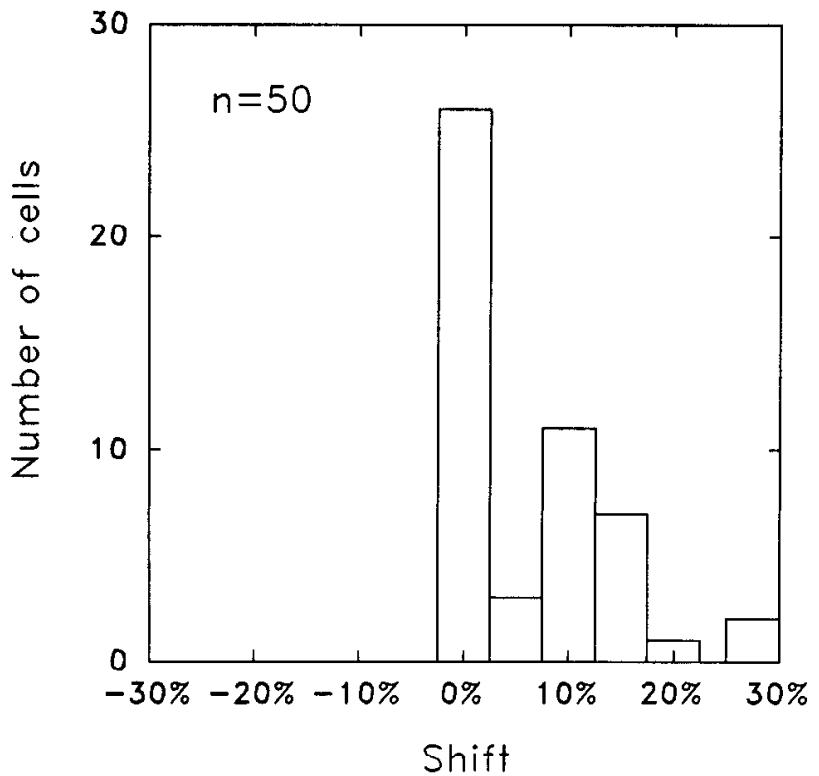

Figure 11. Displacement of receptive fields relative to dendritic fields of the DS ganglion cells. The displacement was measured by estimating the geometric centers of the dendritic and receptive fields along the preferred-null axis. The shift is expressed in percentage terms: it is the absolute distance that the geometric center shifted divided by the averaged diameter of the receptive and dendritic fields along the preferrednull axis. not be made as precisely as for the DS cells, but the result was essentially the same-the receptive and dendritic fields were nearly the same size. Such a match appears to be common for neurons of the inner retina. Whether or not it is universal remains to be seen, because of the existence of large gap junctions on some inner retinal neurons.

\section{Morphological characteristics of the DS cells}

The shape of the DS cells agrees with that described by Amthor et al. (1989), who injected DS cells after recordings made in the central retina. The cells are bistratified, with dendrites that recurve toward the cell body. They give the dendritic arbor a distinctive honeycomb appearance. In the central retina, the dendritic arbors are asymmetric around the cell body. In the periphery, the arbors become larger and rounder. We saw no obvious relationship between the details of the dendritic arbor and any aspect of the receptive field, either in the central retina or the periphery. Conceivably, very detailed mapping would reveal a relationship-it is tempting to inspect the dendritic structures shown in Figures 2, 4, and 5 for local irregularities that might correlate with the receptive field. One must remember, though, that input arrives at the ganglion cell only after passing through the bipolar cells, which themselves have a lateral spread larger than the smaller subdivisions of the ganglion cell's dendritic arbor.

The shapes and dimensions of the dendrites are important for modeling of the cells; together with the channels present in

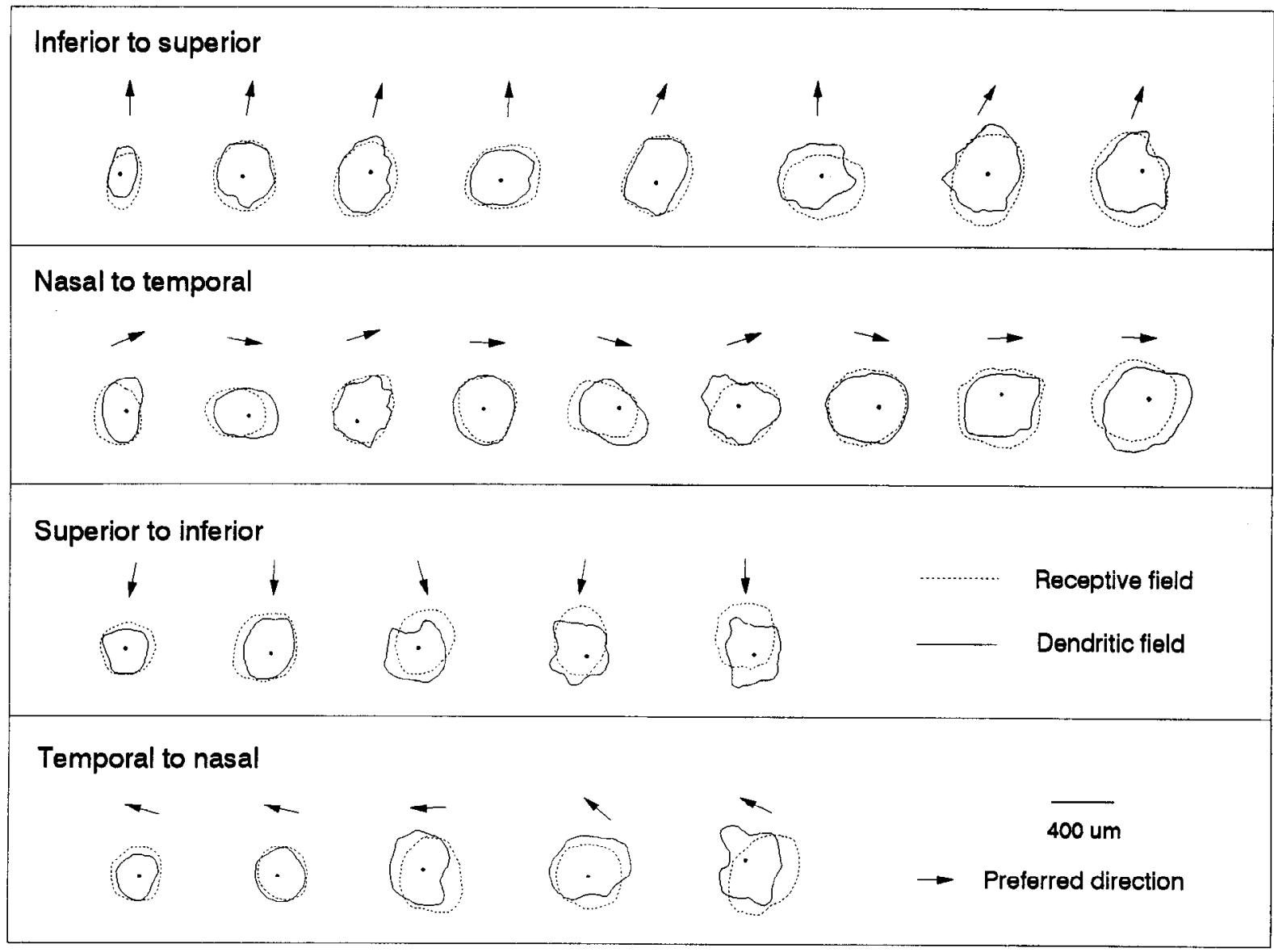

Figure 12. Schematic drawings showing the relationship of receptive and dendritic fields of 27 DS ganglion cells, grouped according to their preferred directions relative to their retinal orientations. In all four groups, some cells show a shift in their receptive field toward the null directions relative to their dendritic fields. 


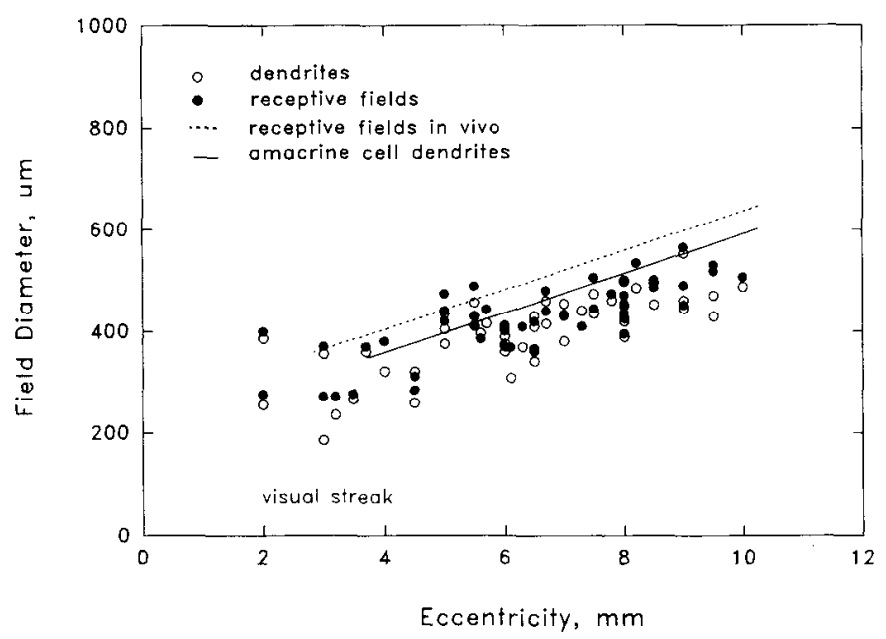

Figure 13. The relationship of receptive and dendritic field sizes of DS cells at various distances from the visual streak. The lines are fitted to scatter plots of the dendritic fields of starburst amacrine cells (Tauchi and Masland, 1984; solid line) and the receptive fields of DS ganglion cells recorded in vivo (Oyster, 1967; dashed line).

the membranes, the physical dimensions of the cells determine the spread of current through the dendrites (Rall, 1964). Ideally, one would like to know the dimensions of the cells in the living state, since fixation causes large and unpredictable changes in the sizes and shapes of cells. In principle, our experiments allow such a measurement. However, even here there are uncertainties. The thickness of the intact retina and the optical density of the photoreceptors decrease the optical quality of the images of the injected cells, even when differential interference contrast is used. More important, the focal plane of the microscope's objective is thicker than the dendrites, so that the whole dendrite is imaged at once. Since more of the visualizing agent (Lucifer yellow or DAB product) is in the optical path at the center of the dendrite than at its edges, the center is brighter (for Lucifer yellow) or optically denser (for DAB) than the dendrite's perimeter. These factors limit one's ability to make an absolute measurement of dendritic diameter, especially when the dendrites are thin, and our measurements represent only a first approximation. With those qualifications, the proximal dendrites appeared to be about $2 \mu \mathrm{m}$ thick (Fig. 6). In the distal third of the dendritic tree the thickness was somewhat under $0.5 \mu \mathrm{m}$. Measurements of dendritic thickness have been made by Famiglietti (1991) from electron microscopy of Golgi-impregnated material. His estimates are roughly $50 \%$ below those given above. Ultrathin sections are optically better than intact tissue. However, the tissue is subject to distortion during the Golgi reaction and to major shrinkage during preparation for electron microscopy. It seems safe to conclude that the thickness of the proximal dendrites lies between 1 and $2 \mu \mathrm{m}$ and the distal between 0.25 and $0.5 \mu \mathrm{m}$, but more precise estimation would be spurious.

A measurement that may be made with more confidence is the extent to which the diameter of the dendrites decreases from proximal to distal (the decrease is important because it has a substantial influence on the dendrites' biophysical behavior). Optical uncertainties and tissue shrinkage should be roughly similar throughout the length of the dendrite, so that the relative measurement is more reliable than the absolute diameter. We find a decrease of roughly a factor of 3 from most proximal dendrites to distal, a value in accord with Famiglietti's.

\section{Coupling between directionally selective ganglion cells}

If neurobiotin or biocytin, low molecular weight tracers, are injected into DS ganglion cells, they sometimes appear in as many as eight neighboring DS ganglion cells (Vaney, 1991). This has been interpreted as evidence for gap junctions between DS ganglion cells. The gap junctions should electrically couple the ganglion cells, so that light falling onto the receptive field of one ganglion cell should tend to excite the neighboring ones as well. This clearly did not happen. The receptive fields were tightly constrained to the region from which an individual ganglion cell collects bipolar inputs-its own dendritic field. The presumed gap junctions did not pass enough current to measurably affect the activity of neighboring ganglion cells.

Only a subset of all DS cells are reported to be tracer coupled. They make up about 30\% of the cells (Vaney, 1991) and one might wonder if they could have been missed by our sample. However, our sample was taken from the same regions of retina studied by Vaney and was large enough that roughly 20 members of the coupled subset should have been included. A directional subset was not excluded, since our sample included cells from all four of the DS cells' cardinal directions (Fig. 12). Even if only a subset of cells are tracer coupled, that subset should have been clearly visible within our sample.

One must also consider the possibility that something about the way these experiments were carried out obscured the tendency of the gap junctions to spread the receptive fields. However, independent confirmation is available from experiments in which Oyster (1967) measured the sizes of the receptive field centers of DS ganglion cells in the rabbit retina in vivo. Figure 13 compares his results with ours. The dashed line is the regression line fitted by him to his sample of 158 DS ganglion cells. The sizes measured by him were slightly larger than ours, but the difference is not enough to affect the conclusion. (In fact, the difference is quite possibly due to light scatter in his experiments, since the optics of a rabbit's eye are worse than the optics of a microscope.) Another possibility is that dark or light adaptation would affect the results. However, Oyster's experiments were carried out on light-adapted animals, while our retinas were dark adapted-the microscope illuminator was turned off after recording began and our preparations were in the dark for the duration of the physiological studies, which usually lasted an hour or more. A near match between dendritic and receptive field sizes thus is observed under a wide variety of conditions.

A conceivable explanation is that neurobiotin and biocytin, which are simply modified amino acids, pass from cell to cell by some means other than a gap junction-possibly a carrier. Another is that the gap junctions are too few or have too high an electrical resistance to have much effect on ganglion cell activity. If this is so, the junctions are few, indeed: for contrast, the effect of gap junctions between horizontal cells is an extension of the receptive field to distances that can be 10 times wider than the cell's dendritic field (Dacheux and Raviola, 1982). Mastronarde (1983) has presented convincing evidence of electrical coupling between $\alpha$-ganglion cells in the cat's retina. However, the effect of the gap junctions was very small and Mastronarde suggested that their role might be to sensitize neighboring cells under near-threshold conditions. Such a mechanism would not have been detected in our experiments. If it exists, though, it must be extremely subtle. 


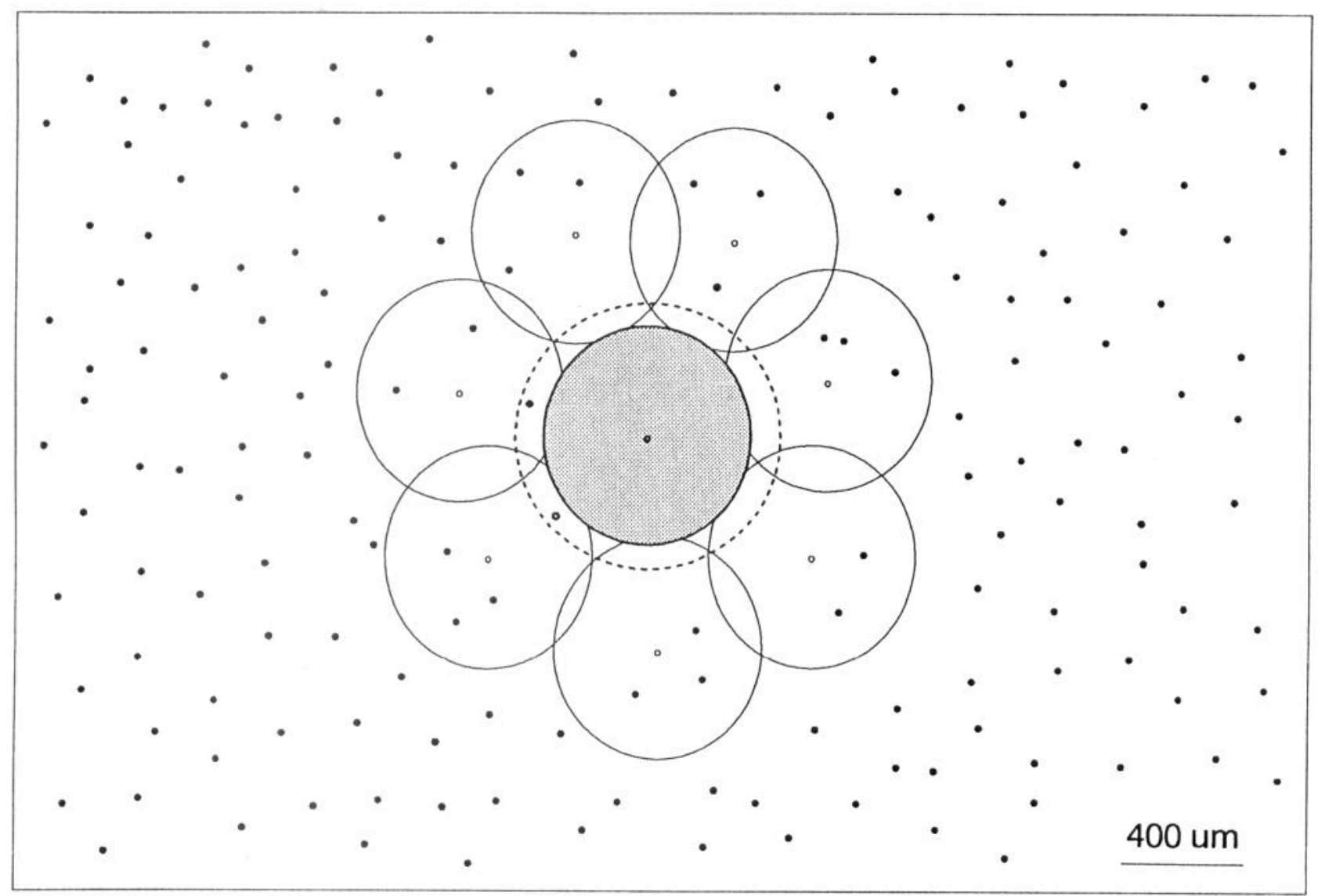

Figure 14. Relationship between the dendritic field of the DS ganglion cell and those of the overlapping starburst amacrine cells. The dendritic field of the DS ganglion cell is shown by the shaded region. The outlines of the dendritic fields of the farthest overlapping starburst cells are shown in a thinner line. (Dots suggest the positions of the somas of other starburst amacrine cells.) If the farthest starburst cells excited the DS ganglion cell, the receptive field of the DS ganglion cell would have almost three times the diameter of its dendritic field. The dashed circle shows the average diameter of the receptive fields that were actually encountered for DS ganglion cells.

\section{The convergence of amacrine cells onto ganglion cells}

The DS ganglion cells receive a direct cholinergic synapse from the starburst amacrine cells. The synapse is excitatory (Masland and Ames, 1976; Masland and Mills, 1979; Famiglietti, 1992). As far as is known (Famiglietti, 1992) the DS cells contact many of the overlying starburst cells, including cells whose dendritic arbors only partially overlap those of the DS cells. At a given retinal eccentricity, the starburst cells' dendritic arbors have approximately the same diameters as those of the DS ganglion cells (Fig. 13). This means that excitation of the overlapping starburst cells should excite the DS ganglion cells. In the limiting case, where the farthest starburst cells are considered, the receptive field of the DS ganglion cell has three times the diameter of the ganglion cell's dendritic field-it should equal the diameter of the DS dendritic field plus two starburst fields (Fig. 14). Something prevents this from happening.

One possibility is that the length constant for electrotonic spread along the starburst cells is relatively short, so that activity does not propagate far along starburst dendrites (Miller and Bloomfield, 1983; Masland et al., 1984; Tauchi and Masland, 1984). Local regions of the starburst dendrites would serve as both input and output structures, restricting lateral spread of activity within the starburst cell. This is perhaps the simplest explanation for the present results.

However, action potentials have now been recorded at the somas of starburst cells (Bloomfield, 1991, 1992a; see also Cook and Werblin, 1992). If these propagate along the dendrites, and if they are the only mechanism by which activity spreads, the local isolation just mentioned would no longer exist. On the other hand, graded potentials were also recorded from the somas of the starburst cells in response to stimulation of the distal dendrites. Those potentials decline fairly steeply as a test spot moves from the distal dendrites to the proximal. This is consistent with electrotonic decrementing, as postulated above. In fact, the area under these potentials is greater than the area under the action potentials, which are relatively few. It is not certain how important the action potentials are for the overall synaptic output of the cells.

In fact, there is direct evidence that $\mathrm{Na}^{+}$action potentials are relatively unimportant for the synaptic action of starburst cells. When tetrodotoxin (TTX) was applied to the retina and the light-stimulated release of acetylcholine was measured, the lightstimulated release of acetylcholine was not decreased. Since the starburst cells are the only cholinergic neurons in the retina, the released acetylcholine must originate at synapses of the starburst cells (Masland and Mills, 1979; Masland et al., 1984; Masland and Cassidy, 1987). The lack of effect of TTX thus indicates that $\mathrm{Na}^{+}$action potentials are not crucial for the synaptic activity of the cells. The conclusion is further supported by Bloomfield's (1992b) finding that the size of the receptive fields of retinal ganglion cells (and starburst cells) is unaffected by TTX. 
More complex solutions to the problem raised by the DS cells' restricted receptive fields can be imagined. Some of them have been mentioned elsewhere (Yang and Masland, 1992). Here, it is perhaps more important to point out that the problem is not peculiar to the DS ganglion cell, or the starburst amacrine cell. There are many types of wide-field amacrine cell, yet many ganglion cells- not just the DS cell-have receptive fields narrower than the spreads of the wide-field amacrine cells (Peichl and Wässle, 1983). The problem can be stated succinctly for the starburst cells, because they make an excitatory synapse directly upon the ganglion cell. However, it exists to a greater or lesser degree for many other amacrine cells, and reflects a major gap in our understanding of the physiology of the inner retina.

\section{References}

Ames A III, Masland RH (1989) The rabbit retina in vitro. In: In vitro preparations from the vertebrate nervous systems (Jahnsen $\mathrm{H}$, ed). New York: Wiley.

Ames A III, Nesbett FB (1980) In vitro retina as an experimental model of the central nervous system. J Neurochem 37:867-877.

Amthor FR, Oyster CW, Takahashi EH (1984) Morphology of ONOFF direction-selective ganglion cells in the rabbit retina. Brain Res 298:187-190.

Amthor FR, Takahashi EH, Oyster CW (1989) Morphologies of rabbit retinal ganglion cells with complex receptive fields. J Comp Neurol 280:97-121.

Ariel M, Daw NW (1982) Pharmacological analysis of directionally selective rabbit retinal ganglion cells. J Physiol (Lond) 324:161-185.

Barlow HB, Levick WR (1965) The mechanism of directionally selective units in the rabbit's retina. J Physiol (Lond) 178:477-505.

Bloomfield SA (1991) Two types of orientation-sensitive responses of amacrine cells in the mammalian retina. Nature 350:347-350.

Bloomfield SA (1992a) Relationship between receptive and dendritic field size of amacrine cells in the rabbit retina. J Neurophysiol 68: 711-725.

Bloomfield SA (1992b) The effects of tetrodotoxin on receptive fields of amacrine and ganglion cells in the rabbit retina. Invest Ophthalmol Vis Sci 33:1173.

Borg-Graham L, Grzywacz NM (1991) A model of the directional selectivity in retina: transformations by neurons singly and in concert. In: Single neuron computation (McKenna T, Davis J, Zornetzer S, eds). Boston: Academic.

Brandon C (1987) Cholinergic neurons in the rabbit retina: dendritic branching and ultrastructural connectivity. Brain Res 426:119-130.

Brecha N, Johnson D, Peichl L, Wässle H (1988) Cholinergic amacrine cells of the rabbit retina contain glutamate decarboxylase and gamaaminobutyrate immunoreactivity. Proc Natl Acad Sci USA 85:61876191.

Cook P, Werblin FS (1992) Action potentials are propagated by widefield amacrine cells in the tiger salamander retina. Invest Ophthalmol Vis Sci [Suppl] 33:1172.

Dacheux RF, Raviola E (1982) Horizontal cells in the retina of the rabbit. J Neurosci 2:1486-1493.

Famiglietti EV (1983) "Starburst" amacrine cells and cholinergic neurons: mirror-symmetric on and off amacrine cells of rabbit retina. Brain Res 261:138-144.

Famiglietti EV (1991) Synaptic organization of starburst amacrine cells in rabbit retina: analysis of serial thin sections by electron microscopy and graphics construction. J Comp Neurol 309:40-70.

Famiglietti EV (1992) Dendritic co-stratification of ON and ON-OFF directionally selective ganglion cells with starburst amacrine cells in rabbit retina. J Comp Neurol 324:322-335.

Grzywacz NM, Amthor FR, Merwine DK (1993) Extra receptive field facilitation in rabbit's retinal directional selectivity. Soc Neurosci Abstr 19:1258.

Koch C, Poggio T, Torre V (1982) Retinal ganglion cells: a functional interpretation of dendritic morphology. Philos Trans $R$ Soc Lond [Biol] 298:227-264.

Kosaka T, Tauchi M, Dahl JL (1988) Cholinergic neurons containing GABA-like and/or glutamic acid decarboxylase-like immunoreactivities in various brain regions of the rat. Exp Brain Res 70:605-617.

Masland RH, Ames A III (1976) Response to acetylcholine of ganglion cells in an isolated mammalian retina. J Neurophysiol 39:1220-1235.

Masland RH, Cassidy C (1987) The resting release of acetylcholine by a retinal neuron. Proc R Soc Lond [Biol] 232:227-247.

Masland RH, Mills JW (1979) Autoradiographic localization of acetylcholine in the rabbit retina. J Cell Biol 81:159-178.

Masland RH, Mills JW, Cassidy C (1984) The functions of acelylcholine in the rabbit retina. Proc R Soc Lond [Biol] 223:121-139.

Mastronarde DN (1983) Interactions between ganglion cells in cat retina. J Neurophysiol 49:350-365.

Miller RF, Bloomfield SA (1983) Electroanatomy of a unique amacrine cell in the rabbit retina. Proc Natl Acad Sci USA 80:3069-3073.

O'Malley DM, Masland RH (1989) Co-release of acetylcholine and GABA by a retinal neuron. Proc Natl Acad Sci USA 86:3414-3418.

Oyster CW (1967) The analysis of retinal image motion by the rabbit retina. PhD thesis, University of California at Berkeley.

Oyster CW (1968) The analysis of image motion by the rabbit retina. J Physiol (Lond) 199:613-635.

Peichl L, Wässle H (1983) The structural correlate of the receptive field centre of $\alpha$ ganglion cells in the cat retina. J Physiol (Lond) 341: 309-324.

Peinado A, Yuste R, Katz LC (1993) Extensive dye coupling between rat neocortical neurons during the period of circuit formation. Neuron 10:103-114.

Rall W (1964) Theoretical significance of dendritic trees for neuronal input-output relations. In: Neuronal theory and modeling (Resis RF, ed), pp 73-97. Palo Alto: Stanford UP.

Tauchi M, Masland RH (1984) The shape and arrangement of the cholinergic neurons in the rabbit retina. Proc R Soc Lond [Biol] 223: 101-119.

Tauchi M, Masland RH (1985) Local order among the dendrites of an amacrine cell population. J Neurosci 5:2494-2501.

Torre V, Poggio T (1978) A synaptic mechanism possibly underlying directional selectivity to motion. Proc R Soc Lond [Biol] 202:409416.

Vaney DI (1984) "Coronate" amacrine cells in the rabbit retina have the "starburst" dendritic morphology. Proc R Soc Lond [Biol] 220: 501-508.

Vaney DI (1990) The mosaic of amacrine cells in the mammalian retina. In: Progress in retinal research, Vol 9 (Osborne N, Chader G, eds), pp 49-100. New York: Pergamon.

Vaney DI (1991) Many diverse types of retinal neurons show tracer coupling when injected with biocytin or neurobiotin. Neurosci Lett 125:187-190.

Vaney DI, Collin SP, Young HM (1989) Dendritic relationship between cholinergic amacrine cells and direction-selective retinal ganglion cells. In: The neurobiology of the inner retina (Weiler R, Osborne N, eds), pp 154-168. Berlin: Springer.

Wyatt HJ, Daw NW (1975) Directionally selective ganglion cells in the rabbit retina: specificity for stimulus direction, size, and speed. J Neurophysiol 38:613-626.

Yang G, Masland RH (1992) Direct visualization of the dendritic and receptive fields of directionally selective retinal ganglion cells. Science 258:1949-1952. 